\title{
The temporal distribution of past and future autobiographical events across the lifespan
}

\author{
R. NATHAN SPRENG and BRIAN LEVINE \\ University of Toronto, Toronto, Ontario, Canada \\ and Baycrest Centre for Geriatric Care, Toronto, Ontario, Canada
}

\begin{abstract}
Knowledge and awareness of past and future autobiographical events may be mediated by a common system that supports intentional, goal-directed behavior. The purpose of this study was to assess the correspondence of past and future autobiographical thought. In Experiment 1, 300 undergraduates aged 19 years generated and assigned dates to past and future autobiographical events. The temporal distribution of past events replicated a power function for retention as has been described in past research. The intention function of future autobiographical events fit the inverse of this same power function, reflecting a temporality of past and future mental time travel centered around the present moment. In Experiment 2, these findings were extended to young, middle-aged, and older groups. These data provide empirical support for the notion that thinking outside of "now" is mediated by a common system, regardless of whether one is thinking about the past or the future.
\end{abstract}

Human beings conceive the future and the past in a dynamic interaction from which complex behaviors emerge in the ongoing present moment. This interaction requires knowledge, conscious awareness, and the use of both past and future autobiographical information. Although autobiographical memory has been studied far more than future autobiographical thought, the latter is arguably of considerable importance to human survival, facilitating predictive control of one's environments, constraining behavior, and giving direction to what would otherwise be stimulus-bound actions.

Regardless of whether one conceives past and future autobiographical thought as related within a hierarchical memory system (i.e., the self-memory system; Conway $\&$ Pleydell-Pearce, 2000) or within an advanced form of consciousness enabling mental time travel (i.e., autonoetic consciousness; Tulving, 2002; Wheeler, Stuss, \& Tulving, 1997), these two forms of autobiographical thought are considered to have a common substrate (Atance \& O'Neill, 2001; Suddendorf \& Corballis, 1997; Wheeler et al., 1997). If this is the case, then measures of past and future autobiographical thought should be correlated. Evidence for this correspondence can be found in studies of healthy adults, child development, psychiatric patients, neuropsychological patients, and functional neuroimaging.

Healthy adults' descriptions of both past and future events show decreasing phenomenological richness with increasing time from the present (D'Argembeau \& Van der Linden, 2004). The development of past and future

The authors thank Morris Moscovitch and Stephen Strother for comments on an earlier version of this article. We gratefully acknowledge the technical assistance of Rachel Bernatchez, Malcolm Binns, and Pheth Sengdy. Address correspondence to R. N. Spreng, Rotman Research Institute, Baycrest Centre for Geriatric Care, 3560 Bathurst Street, Toronto, ON, M6A 2E1 Canada (e-mail: nathan.spreng@gmail.com). mental time travel emerges simultaneously and codependently between the ages of 3 and 5 (Atance \& O'Neill, 2005; Levine, 2004; Nelson \& Fivush, 2004; Suddendorf $\&$ Busby, 2005; Wheeler et al., 1997); however, confusion over the distinction between the past and future status of events may persist until 6 years of age (Friedman, 2005). In patients with depression, the specificity of autobiographical memory retrieval is related to strategic problem-solving ability (Evans, Williams, O'Loughlin, \& Howells, 1992; Goddard, Dritschel, \& Burton, 1996) and imageability of the future (Williams et al., 1996). Similarly, patients with frontal lobe damage causing disorders of planning and self-regulation have been shown to have co-occurring deficits in episodic recollection (Burgess, Veitch, de Lacy Costello, \& Shallice, 2000; Levine, Freedman, Dawson, Black, \& Stuss, 1999; Worthington, 1999), and amnesic patients can demonstrate an inability to envisage the future (Dalla Barba, Cappelletti, Signorini, \& Denes, 1997; Klein, Loftus, \& Kihlstrom, 2002; Tulving, 1985). A common neural substrate to past and future autobiographical thought is further corroborated by a functional neuroimaging study in which frontal polar and medial temporal activation was associated with both these forms of mental activity (Okuda et al., 2003).

The present study examined the relationship between past and future autobiographical thinking in healthy adults. This was accomplished with a modification of a cued word recall technique originated by Galton (1879). The analysis of dates assigned to autobiographical events generated by this method reveals a distribution characterized by a preponderance of events in the recent past and (with the exception of the early adult "reminiscence bump" and the period of childhood amnesia) a monotonic decline in event frequency with increasing time into the past (Crovitz \& Schiffman, 1974). These findings have been extensively replicated and extended to a variety 
of cuing methods and participant groups (Rubin, 1982; Rubin \& Schulkind, 1997).

We examined the correspondence of past and future autobiographical thought by applying the cue-word method to both the past and the future. In response to cue words, participants generated personal past events and highly probable personal future events that were specific in time. Given the evidence in favor of the correspondence between past and future autobiographical thought, we predicted that the temporal distribution of future events plotted over the participants' projected future lifespan (the intention function) would mirror the temporal distribution of past events plotted over the past lifespan (the retention function) as a power function (straight line on a log-log scale). The cueword method allowed us to sample a large number of past and future autobiographical events in a comparable manner, reducing the possibility of a measurement confound between these two aspects of autobiographical thought.

Our design also allowed for the incorporation of future time perspective (FTP; Wallace, 1956). The extension of FTP is defined as the median date assigned to future events. Foreshortened FTP extensions have been observed in schizophrenics (Wallace, 1956), heroin addicts (Petry, Bickel, \& Arnett, 1998), and patients with frontal lobe lesions (Fellows \& Farah, 2005). We also calculated temporal perspective for past events, or past time perspective (PTP). An ancillary goal of this study was to determine the relationship of these measures, characterizing past and future temporal orientation via single points in time to the above-described measures, which utilize the entire corpus of generated events to illustrate the distribution of past and future autobiographical events across the lifespan.

The first experiment examined past and future thinking in young undergraduates. Because of the effect of age on temporal orientation, we conducted a second experiment in which past and future events were sampled from young, middle-aged, and older adults. Both experiments were conducted using Web-based methodology, which has been shown to reliably replicate laboratory findings and to enable the testing of a greater number of participants (Gosling, Vazire, Srivastava, \& John, 2004).

\section{EXPERIMENT 1}

\section{Method}

Participants. A total of 349 University of Toronto first-year psychology students $(37 \%$ male) with a mean age of 18.9 years $(S D=$ 0.8 ) participated in exchange for course credit in psychology. Exclusionary criteria included: a history of head injury with a loss of consciousness greater than $15 \mathrm{~min}$, a major psychiatric disorder, other medical conditions affecting cognitive functioning or memory, and current and regular use of benzodiazapines.

Materials. The Modified Future Crovitz Test (MFCT) is a Webbased test that includes 90 cue words selected from Rubin (1980). The words were broken into two lists and their properties (Rubin, 1980) were matched for length in letters, imagery, concreteness, fluency, and emotionality (confirmed by ANOVA, all $p \mathrm{~s}>.40$ ). The word lists were counterbalanced across past and future sections.

Procedure. The MFCT comprised three sections: past, future, and dating. For each word in the past and future sections, each participant entered a brief description of "a single and specific past event," involving the participant, "that has already happened," or "a single and specific future event," involving the participant, "that is very likely to happen." A personal event was defined to the participants as one occurring in a specific place and time in which they are the main character. Although there was no time limit, participants were encouraged to proceed to the next item if they had not completed their event description after $1 \mathrm{~min}$.

Following completion of the past and future sections, participants recorded how long ago/until the event occurred/would occur in terms of how many minutes, hours, days, months, and years from the present. The date of each event was converted into a single value reflecting the number of hours of its occurrence from the present, thus forming the main dependent measure of interest in this study. This section of the test was untimed. The order of the presentation of the past and future lists was counterbalanced across participants.

Given our use of Web-based data collection, several steps were taken to ensure compliance. Participants were instructed to enter the current time at three different points during the test. No time lapses greater than 2 min were observed. Each of the 31,410 event descriptions generated for this study was reviewed. When participants deviated from the instructions on more than 10 occasions within a past or future section (e.g., descriptions of nonevents), they were excluded from analysis. This resulted in the exclusion of 49 participants. To assess for bias that may have occurred by excluding this large number of participants, the analyses were conducted on both the full sample of 349 participants and the verified sample of 300 participants. There were no differences in the results from these two analyses. We elected to report data from the verified sample of 300 .

Analysis. Participants generated an average of $43.0(S D=5.5)$ past and $42.0(S D=4.3)$ future events $(\max =45)$, resulting in a total of 12,882 past events and 12,550 future events $(\max =13,500)$. Following Rubin (1982), the temporal distribution of events was calculated by pooling event dates across participants. Eighty years of time were divided into 11 equal bins on a logarithmic scale. The number of events falling within each bin was calculated.

The axial coordinates for the distribution of events per hour as a function of "hours from present" were calculated as a power function, following established methods (Rubin, 1982; Rubin \& Schulkind, 1997). The $x$-coordinates were determined by taking the log of the bin's midpoint, with negative and positive time values indicating temporal directionality. The $y$-coordinates were calculated as the log of the quotient of the frequency of each response, divided by the bin range. The fit to the power function and the slope parameter were calculated. The nontransformed dependent variables of the past and future were also fit with linear, logarithmic, quadratic, and exponential regression models.

To examine the correspondence of dating past and future events, the linear correlations of the past and future logarithmic-transformed data sets were calculated using Pearson's $r$. Supplementary correlational analyses were conducted on the raw event dates for past and future events and were rank ordered for each participant in order to rule out artifact owing to logarithmic transformation. The mean and standard deviation of this within-subjects correlation were calculated across participants.

FTP and PTP were estimated with the median values of participants' past and future event dates (Wallace, 1956). Participants' median temporal perspectives of the future and past were compared with a paired-samples $t$ test.

\section{Results and Discussion}

The retention function of past autobiographical events and the intention function of future autobiographical events provided a good fit to the power function (see Table 1: contains data for Experiments 1 and 2), fitting as a straight line on a logarithmic scale (see Figure 1). Comparing the slope of the temporal distribution of autobiographical memories across studies is a common 
method for determining whether distributions are similar (Rubin \& Wenzel, 1996). We observed a slope parameter for the past distribution in agreement with previously attained values (see Table 1; Crovitz \& Schiffman, 1974; Rubin, 1982). Replication of both the power function and the slope parameter from prior autobiographical memory studies supports the validity of the online version of the cue-word test. The slope of the prospective autobiographical event distribution was somewhat steeper, indicative of a greater number of events occurring near the present (see Table 1). Figure 1 shows a frequency of retrospective and prospective events occurring near the present and declining as a function of temporal distance from the present.

We fit retention and intention as a straight line on two logarithmically transformed scales. However, this is not the only model to which the data may be fit. Another mode of comparison of $R^{2}$ values may be executed with the nontransformed dependent variable. The values of the linear, logarithmic, and quadratic functions provide a weaker fit to the data, whereas the exponential function is equivalent to the power functions of the past and future distributions (see Table 1).

The logarithmically transformed past and future data sets correlated very highly $[r(298)=-.996, p<.001]$. The mean within-subjects correlation of the rank order of past and future events was $-.81(S D=.15)$. These correlations mark a strong concordance between past and future events that cannot be accounted for by data transformations. Participants' FTP $(M=1.12$ years; $S D=$ 2.52) was significantly shorter than their PTP $(M=2.73$ years; $S D=3.32)[t(299)=8.07, p<.001]$, suggesting that individuals in this age group tend to think nearer to the present when considering the future than when thinking about the personal past. Given the young age of these participants, however, temporal horizons are unbalanced. These data will be discussed further in relation to Experiment 2.

\section{EXPERIMENT 2}

Age is likely a major determinant of past and future autobiographical thought. Younger and older adults show similar distributions of events across the past decade (Rubin \& Schulkind, 1997). Assuming a strong relationship between past and future autobiographical thought- as demonstrated in Experiment 1-we predicted that a similar invariance would hold for future events. On the other hand, young adults possess a greater potential for an extended future, whereas the elderly own a greater depth of past experiences. By virtue of these age differences, PTP and FTP might differ across groups, with greater temporal extension of the future and past in younger and older adults, respectively. In Experiment 2, these predictions were tested in three age groups.

\section{Method}

Participants. Participants were tested in three age groups: young ( $n=50,22 \%$ male, mean age 25.4 years, $S D=3.4)$, middle-aged $(n=50,16 \%$ male, mean age 50.5 years, $S D=7.5)$, and older $(n=$ $35,23 \%$ male, mean age 72.5 years, $S D=5.3$ ). Exclusion criteria were as those in Experiment 1.

Materials. The materials were identical to those in Experiment 1, except that 40 cue words were used instead of 90 in order to reduce the amount of total test time. This reduction in cue words has been found to have no effect on the temporal distribution of autobiographical memory (Rubin, 1982). Further confirmation of this finding was sought by examining the temporal distributions of events generated for these same subset 40 words in the Experiment 1 participants. We found that restricting the number of events in this way did not affect the results.

Procedure. The procedure was identical to that in Experiment 1, except that 21 older participants performed the experiment on site. Remuneration included course credit in psychology, participation in a lottery for $\$ 50$, donation to charity on their behalf, or $\$ 20$ for participation on site.

Participants were recruited from the University of Toronto firstyear psychology Web site, from the Rotman Research Institute subject pool, and through advertisements. Compliance was assessed in the same manner as in Experiment 1. Five young, 11 middle, and 8 older adults were excluded, using the same criteria as that described previously.

Analysis. Participants generated an average of $18.8(S D=2.2)$ past and $18.1(S D=2.5)$ future events $(\max =20)$. Young adults provided 922 past events and 904 future events, whereas middle-aged adults provided 959 past events and 934 future events $(\max =1,000$; i.e., 50 subjects $\times 20$ events). Older adults provided 653 past events and 600 future events ( $\max =700$; i.e., 35 subjects $\times 20$ events).

The temporal distributions of autobiographical events, correlations, and curve fitting were calculated as those in Experiment 1. The correspondence of temporal distributions of past and future events across age groups was examined by correlating event dates using Pearson's $r$. Future and past time perspectives were calculated as those in Experiment 1. Group differences in these data were assessed with a $2 \times 3$ mixed-design ANOVA. Post hoc paired comparisons were made using Tukey's HSD, $p<.05$.

Table 1

Slope and $\boldsymbol{R}^{2}$ s of All Groups' Event Distributions for the Past and the Future (Experiments 1 and 2)

\begin{tabular}{|c|c|c|c|c|c|c|c|c|}
\hline & \multicolumn{4}{|c|}{ Retention } & \multicolumn{4}{|c|}{ Intention } \\
\hline & Youngest & Young & $\begin{array}{c}\text { Middle- } \\
\text { Aged }\end{array}$ & Old & Youngest & Young & $\begin{array}{c}\text { Middle- } \\
\text { Aged }\end{array}$ & Old \\
\hline Power function slope & 0.84 & 0.90 & 0.92 & 0.91 & -1.07 & -1.00 & -1.16 & -1.21 \\
\hline Power function $R^{2}$ & .982 & .957 & .977 & .981 & .984 & .979 & .972 & .962 \\
\hline Exponential $R^{2}$ & .982 & .973 & .981 & .984 & .995 & .980 & .988 & .962 \\
\hline Quadratic $R^{2}$ & .858 & .764 & .941 & .836 & .883 & .838 & .907 & .874 \\
\hline Logarithmic $R^{2}$ & .783 & .680 & .897 & .773 & .867 & .800 & .878 & .857 \\
\hline Linear $R^{2}$ & .631 & .583 & .634 & .583 & .518 & .502 & .559 & .510 \\
\hline
\end{tabular}

Note-The youngest group comprises participants from Study 1. Young, middle-aged, and old participants are from Study 2 . 


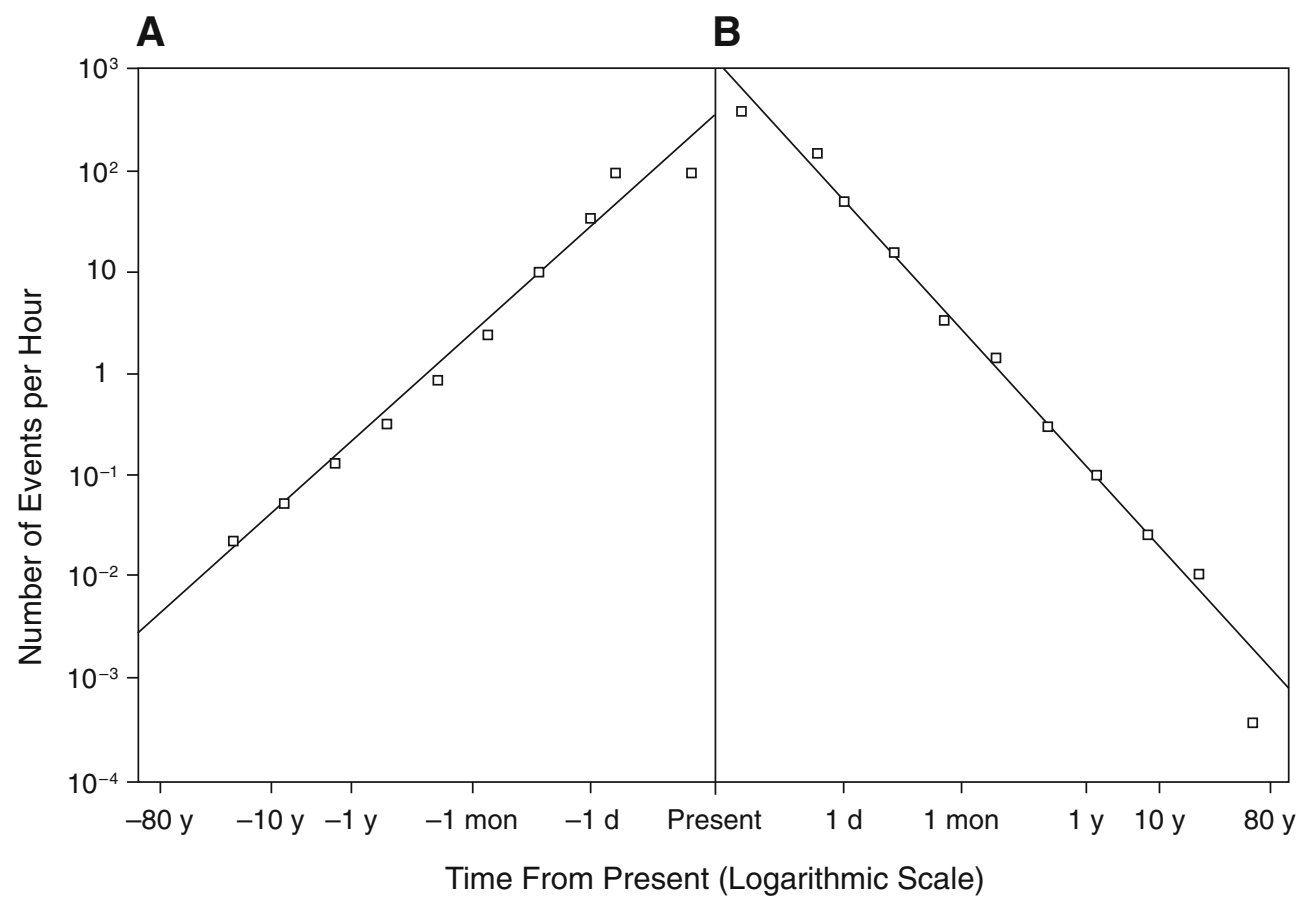

Figure 1. The temporal distribution of autobiographical event frequency per hour, plotted as a function of time from the present (days, months, years) in Experiment 1. (A) Retention. (B) Intention.

\section{Results and Discussion}

The retention functions of retrospective autobiographical events for young, middle-aged, and older adults provided a good fit to the power function with similar slope values (see Table 1), once again replicating prior results (Rubin \& Schulkind, 1997). We also examined the linear correlations of the distribution of memories between different age groups. High correlations of the distribution of memories across age groups (ranging from .967 to .997 ; all $p \mathrm{~s}<.001$ ) replicated previous work (Rubin \& Schulkind, 1997). That is, adults of all ages in this study generated events from the near past with greatest frequency; the number of these events declined as a function of time.

As found in Experiment 1, the intention function behaved in a manner similar to the retention function (see Figure 2). The intention functions of prospective autobiographical events provided a good fit to the power function (see Table 1). The slope parameters of the future data sets for young, middle aged, and older adults were higher than those for the past (see Table 1), indicating a greater number of events occurring near the present moment. These results suggest that intended events take place closer to the present and become less frequent in time with age. Indeed, older adults did not generate a single event extending past 15 years. In spite of the differences in the slope of the distributions of future events, these distributions were highly correlated across age groups, with $r$ s ranging from .969 to .992 (all $p$ s $<.001)$.

In fitting nontransformed data with linear, logarithmic, quadratic, and exponential regression models, we found the best fit with the exponential regression models for in- tention and retention in all three groups-comparable to the power function - with less variance accounted for by the other models (see Table 1).

The logarithmically transformed past and future data sets for within the young, middle-aged, and older adult groups correlated very highly: $[r(50)=-.964, p<.001$; $r(50)=-.962, p<.001$; and $r(35)=-.975, p<.001$, respectively]. The mean within-subjects correlation of the raw data set within the young, middle-aged, and older adult groups for past and future events were $-.79(S D=$ $.14),-.75(S D=.20)$, and $-.79(S D=.17)$, respectively. As in Experiment 1, these high correlations demonstrate a remarkable concordance in the frequency and recency of past and future thinking when engaged in mental time travel.

Time perspective was compared for the past and the future with the three age groups in a repeated measures ANOVA. A significant interaction of age and temporal perspective was observed $[F(2,132)=5.86, p=.004]$. Simple main effects were found for age group at FTP $[F(2,132)=4.09, p=.02]$, and PTP $[F(2,132)=4.67$, $p=.01]$. Young people differed from the older adults in that they had a significantly higher FTP and a significantly lower PTP. Middle-aged adults' data were positioned between these values (see Table 2). These data suggest that as people age, reminiscences extend further back in time; conversely, future orientation draws closer to the present.

There was also a simple main effect of time for age $[F(2,132)=7.79, p=.001]$. FTP was significantly lower than PTP for young, middle age, and older adults (see Table 2). These data suggest that the temporal extension 


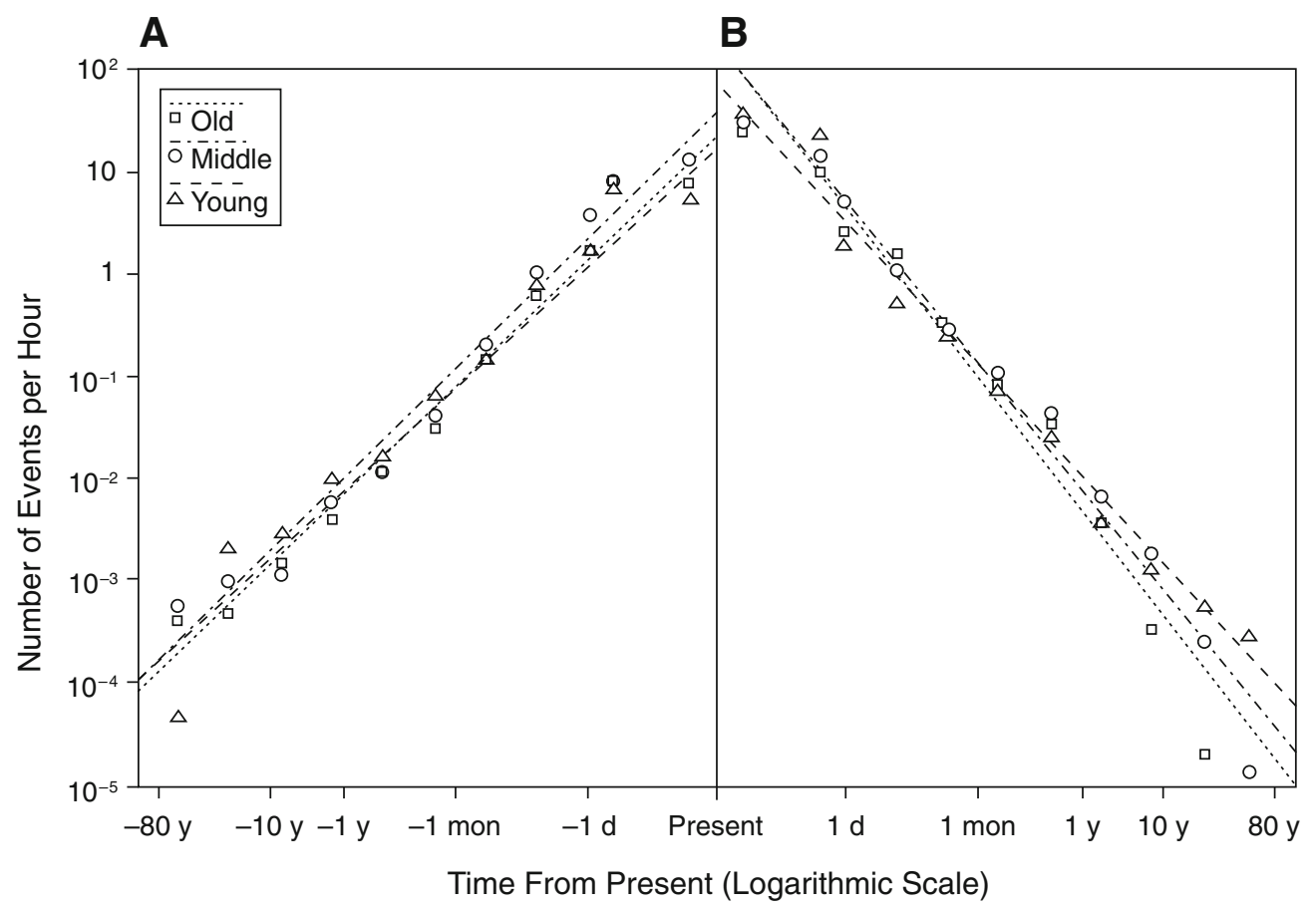

Figure 2. The temporal distribution of autobiographical event frequency per hour, plotted as a function of time from the present (days, months, years) for the young, middle-aged, and older adult groups in Experiment 2. (A) Retention. (B) Intention.

of the self into the future is always closer to the present than one's extension into the past.

\section{GENERAL DISCUSSION}

Although past and future autobiographical thought have been hypothesized to be mediated by shared cognitive systems (Atance \& O'Neill, 2001; Conway \& PleydellPearce, 2000; Suddendorf \& Corballis, 1997; Tulving, 2002; Wheeler et al., 1997), their interrelationship has received little empirical attention. The present study is an initial attempt at exploring the correspondence between past and future autobiographical thought. The findings provide evidence in favor of a correspondence between these two forms of thought via congruency between temporal distributions of autobiographical retention and intention.

This demonstration required the validation of a new construct: the intention function, defined as the temporal distribution of autobiographical intentions. We began by replicating prior results on the retention function, a previously very well-established construct in the autobiographical memory literature (Crovitz \& Schiffman, 1974; Rubin, 1982; Rubin \& Schulkind, 1997). The power function provides an excellent fit for the data, whereas other models provide varying degrees of goodness of fit. Linear, logarithmic, and quadratic models provide varying degrees of fitness, whereas exponential models match the data as well as the power function. However, curve fitting alone does not determine the best-fitting functions: Both descriptions of the data and theoretical considerations are required (Rubin \& Wenzel, 1996). Regardless of whether the transformed or nontransformed data are fit, the power function provides an excellent description of the data, leaving less than $5 \%$ of the variance unaccounted for.

Power functions can be fit to a number of psychological phenomena as an appropriate mathematical description of human performance in the psychophysics of sensation (Stevens, 1961, 1970), skill acquisition (Logan, 1988), as well as retention (Rubin, 1982; Rubin \& Wenzel, 1996). One shortcoming of the present study is an absence of a tested dissociation, where a behavior does not fit a power function. Accordingly, we cannot rule out the possibility that the similarity in the mathematical form of retention and intention functions reflects shared nonspecific elements of the event-dating process. Yet, if we assume that the subjective intensity of the memory trace declines as a function of time in the same way that the subjective intensity of an intention would diminish as a function of temporal distance from the present, then the power law of auto-

Table 2

Time Perspective of Age Groups in Years

\begin{tabular}{crrrrr}
\hline & \multicolumn{2}{c}{ Past } & & \multicolumn{2}{c}{ Future } \\
\cline { 2 - 3 } \cline { 5 - 6 } Age Group & \multicolumn{1}{c}{$M$} & $S D$ & & $M$ & $S D$ \\
\hline Young & 6.4 & 5.1 & & 2.6 & 4.1 \\
Middle & 14.0 & 12.4 & & 1.2 & 1.8 \\
Old & 18.4 & 15.6 & & 0.3 & 0.3 \\
\hline
\end{tabular}


biographical planning should be derived from the retention function, as has been predicted by theories emphasizing commonalities among past and future autobiographical thought (Atance \& O'Neill, 2001; Conway \& PleydellPearce, 2000; Suddendorf \& Corballis, 1997; Tulving, 2002; Wheeler et al., 1997). Most importantly, our findings replicate those derived from entirely different methods (see, e.g., D'Argembeau \& Van der Linden, 2004). A conservative conclusion could be restricted to the relationship between personal events and time: Autobiographical remembering - like autobiographical planning - obeys a power law.

The intention and retention functions demonstrate the greatest frequency of events near the present, declining in frequency as a function of time. Stated another way: As one moves forward through life, the future rises up to meet the present moment as the past falls away. These distributions appear to remain largely constant across the lifespan, since our four age groups revealed the same pattern of event frequency over time.

These data were collected via Web-based administration, allowing for the testing of a larger number of participants at a cost of decreased experimenter-participant contact (Gosling et al., 2004). The drawbacks of Web-based administration were offset by the ability to collect data from 508 participants, increasing the stability of the data. Several steps were taken to ensure the integrity of the data. The most important finding in support of our method was the fact that we replicated the well-established retention function (Crovitz \& Schiffman, 1974; Rubin, 1982; Rubin \& Schulkind, 1997).

Event generation via the Galton-Crovitz cue-word technique draws upon multiple cognitive processes, including generative retrieval, monitoring, and error correction, as well as episodic and semantic autobiographical memory. Although this technique was necessary in order to collect a sufficient number of events to reliably characterize the temporal distribution of past and future autobiographical thought, it did not allow us to delineate precisely which cognitive processes account for the correspondence between past and future autobiographical thought, as was demonstrated by this study. Nonetheless, broadly considered, the data fit predictions drawn from theories concerning memory and the self.

According to Conway and Pleydell-Pearce (2000), personal goals modulate the construction of autobiographical memories within a self-memory system. The reciprocal relationship between past and future autobiographical thought helps to regulate behavior in an adaptive manner. Tulving (1985, 2002; Wheeler et al., 1997) proposed that both past and future autobiographical thought are mediated by autonoetic (self-knowing) consciousness, which enables awareness of the existence of the self as a continuous entity across time.

Temporal construal theory predicts that near-future events are more concretely and contextually represented, whereas distant future events are more abstract and decontextualized (Trope \& Liberman, 2003). Near-future events may increase in frequency as the abstract is articu- lated into component parts, allowing for the execution of intentions. Conversely, recent memories are likely more relevant to ongoing behavior-increasing the likelihood of recollection-whereas distant past events decay with time, causing forgetting (Rubin, 1982).

Our findings are consistent with those of D'Argembeau and Van der Linden (2004), who-utilizing a modified memory characteristics questionnaire (Johnson, Foley, Suengas, \& Raye, 1988) — found that both past and future event types generated within one year were described with more detail than events that occurred five to 10 years from the present. Similarly, memories of the recent past are linguistically represented in more concrete and contextually rich terms than more distant, abstractly represented memories (Semin \& Smith, 1999). These studies complement the present study by providing content analysis of events in time as opposed to event frequencies.

Memory can guide future behaviors through knowledge and exemplars (Klein, Cosmides, Tooby, \& Chance, 2002). Indeed, specific past events can serve as a directive function for future problems (Pillemer, 2003). In this way, there is a dynamic interaction between the past and future in molding behavior. Working memory bridges temporal discontinuities, integrating information from long-term memory stores in conjunction with perceptual information into plans for the future (Fuster, 1985). Future plans - or "memories of the future" (Ingvar, 1985) - form the basis for anticipation and expectation. They also form the basis for the short- and long-term planning of a goal-directed behavioral and cognitive repertoire that is based upon experiences of past events and the awareness of the present and is continuously rehearsed and optimized (Ingvar, 1985).

According to Fuster (1985) and Ingvar (1985), these processes are mediated by the prefrontal cortex - a hypothesis supported by a functional neuroimaging study in which past and future thought were directly contrasted (Okuda et al., 2003). Okuda and colleagues found that future thinking (particularly for temporally distant events) was associated with activity in the anteromedial prefrontal cortex, a region associated with both autobiographical memory retrieval (Svoboda, McKinnon, \& Levine, 2006) and prospective memory (Burgess, Scott, \& Frith, 2003; Okuda et al., 1998). Moreover, the medial temporal lobes - known to mediate the retrieval of past events (Squire \& Zola-Morgan, 1991) — were activated for both past and future events. Some medial temporal areas were more activated for future than for past, suggesting that retrieval of past events figures prominently in generating future thought. The present study further supports the notion of a dynamic interplay between past and future thought that is mediated by frontotemporal interactions. To the extent that future thought is yoked to autobiographical memory, the intention function should mirror the retention function, as was found in the present study.

Past and future time perspectives provide another manner of examining the same data via representation of the central tendency of the event distribution. PTP and FTP were found to be different from one another across all age groups. We found that participants' thoughts about the 
future are closer to the present than their thoughts about the past, and that participants think about the near future more often than the near past - as was indicated by the higher slopes of the intention functions in comparison with the retention functions. These data suggest that the envisaged future is temporally closer to the self than the remembered past. The preeminence of the immediate future outweighs the near past by matter of necessity. Ongoing demands require more elaborate, concrete plans over distant, abstract ones. Indeed, highly elaborated concrete plans for the distant future would not be economical when so many contingencies might cause disruption. Rising above stimulus-bound actions, these near-term intentions may direct present behavior in a goal-oriented manner. As such, the temporal distribution of autobiographical events diminishes as a function of time, and FTP is closer to the present than past events.

As expected - given the extent of future prospects for youth and the reservoirs of memory for the old-younger adults tended to think further into the future, whereas the older adults tended to think about the distant past, and the middle-aged group occupied a middle ground. Taking childhood amnesia into consideration (Bruce, Dolan, \& PhillipsGrant, 2000), the young group in our study selected events from a time period spanning an average of 20-21 years. In contrast, the middle-aged group and the older adult group selected events from 46- and 68-year time periods, respectively. Even when factoring in forgetting, the greater PTP for older adults and its decline with youth is a matter of drift in central tendency. Likewise, FTP contracts with age when very distant plans become irrelevant, given the constraints of mortality. Under duress or impending change, the frequency of future autobiographical planning may change. However, all groups produced intentions, which may guide behavior through the present moment. Similar findings have been observed in measures of temporal extension derived from a timeline task involving listing and dating significant life events (de Vries \& Watt, 1996; Schroots, van Dijkum, $\&$ Assink, 2004). The temporal distribution of events across the lifespan, however, expands the scope of this analysis, providing a fuller picture of cognitive operations pertaining to autobiographical time.

Our data did not allow for deconstruction of future thinking into constituent systems or processes, as has been done for memory. Indeed, there is very little research upon which to base such distinctions (see Haith, 1997; for exception, see Okuda et al., 2003). This does not, however, mean that future thought is homogeneous. For example, repeated future events may be dissociated from singleinstance future events, as is the case within memory (see, e.g., Conway, 1992). Moreover, future thought is likely modulated by individual differences in personality or cognitive styles (see, e.g., Drakulić, Tenjović, \& Lečić-Toševski, 2003; Zimbardo \& Boyd, 1999). Further research delineating subcomponents of future-oriented thinking will be necessary to examine its mechanisms.

Investigation into future-oriented thinking and its relationship with memory have only recently begun to attract serious attention. The importance of this cognitive capacity - which may be unique to humans (Roberts, 2002; Suddendorf \& Busby, 2003) - is apparent in patients with brain damage in the prefrontal cortex and medial temporal lobes who have lost the ability to travel mentally in time and are confined to stimulus-bound actions (Tulving, 1985; Wilson \& Wearing, 1995). This capacity may even have contributed to the notion of progress and hence the development of civilization itself (Tulving, 2002). The obedience of past and future temporal distributions to the power law is consistent with the hypothesis that these two forms of autobiographical thought draw upon shared systems mediating mental time travel, although the contribution of less specific processes (e.g., problem solving) cannot be ruled out. Further research will continue to delineate the cognitive and neural mechanisms of this relationship toward a science of future thinking.

\section{REFERENCES}

Atance, C. [M.], \& O’Neill, D. K. (2001). Episodic future thinking. Trends in Cognitive Sciences, 5, 533-539.

AtANCE, C. M., \& O'NeILL, D. K. (2005). The emergence of episodic future thinking in humans. Learning \& Motivation, 36, 126-144.

Bruce, D., Dolan, A., \& Phillips-Grant, K. (2000). On the transition from childhood amnesia to the recall of personal memories. Psychological Science, 11, 360-364.

Burgess, P. W., ScotT, S. K., \& Frith, C. D. (2003). The role of the rostral frontal cortex (area 10) in prospective memory: A lateral versus medial dissociation. Neuropsychologia, 41, 906-918.

Burgess, P. W., Veitch, E., De Lacy Costello, A., \& Shallice, T. (2000). The cognitive and neuroanatomical correlates of multitasking. Neuropsychologia, 38, 848-863.

CoNWAY, M. A. (1992). A structural model of autobiographical memory. In M. A. Conway, D. C. Rubin, H. Spinnler, \& W. A. Wagenaar (Eds.), Theoretical perspectives on autobiographical memory (pp. 167-193). Dordrecht: Kluwer.

Conway, M. A., \& Pleydell-Pearce, C. W. (2000). The construction of autobiographical memories in the self-memory system. Psychological Review, 107, 261-288.

Crovitz, H. F., \& SCHIFFMAN, H. (1974). Frequency of episodic memories as a function of their age. Bulletin of the Psychonomic Society, 4, 517-518.

Dalla Barba, G., Cappelletti, J. Y., Signorini, M., \& Denes, G. (1997). Confabulation: Remembering "another" past, planning "another" future. Neurocase, 3, 425-436.

D'Argembeau, A., \& VAN DeR Linden, M. (2004). Phenomenal characteristics associated with projecting oneself back into the past and forward into the future: Influence of valence and temporal distance. Consciousness \& Cognition, 13, 844-858.

DE VRIES, B., \& WATT, D. (1996). A lifetime of events: Age and gender variations in the life story. International Journal of Aging \& Human Development, 42, 81-102.

Drakulić, B., TenJović, L., \& LeČIĆ-TošEvski, D. (2003). Time Integration Questionnaire: Construction and empirical validation of a new instrument for the assessment of subjective time experience. European Journal of Psychological Assessment, 19, 101-116.

Evans, J., Williams, J. M., O'Loughlin, S., \& Howells, K. (1992). Autobiographical memory and problem-solving strategies of parasuicide patients. Psychological Medicine, 22, 399-405.

Fellows, L. K., \& FARAH, M. J. (2005). Dissociable elements of human foresight: A role for the ventromedial frontal lobes in framing the future, but not in discounting future rewards. Neuropsychologia, 43, 1214-1221.

FRIEDMAN, W. J. (2005). Developmental and cognitive perspectives on humans' sense of the times of past and future events. Learning \& Motivation, 36, 145-158.

Fuster, J. M. (1985). Temporal organization of behavior. Human Neurobiology, 4, 57-60. 
Galton, F. (1879). Psychometric experiments. Brain, 2, 149-162.

Goddard, L., Dritschel, B., \& Burton, A. (1996). Role of autobiographical memory in social problem solving and depression. Journal of Abnormal Psychology, 105, 609-616.

Gosling, S. D., Vazire, S., Srivastava, S., \& John, O. P. (2004). Should we trust Web-based studies? A comparative analysis of six preconceptions about internet questionnaires. American Psychologist, 59, 93-104.

HAITH, M. M. (1997). The development of future thinking as essential for the emergence of skill in planning. In S. L. Friedman \& E. K. Scholnick (Eds.), The developmental psychology of planning: Why, how, and when do we plan? (pp. 25-42). Mahwah, NJ: Erlbaum.

INGVAR, D. H. (1985). "Memory of the future": An essay on the temporal organization of conscious awareness. Human Neurobiology, 4, 127-136.

Johnson, M. K., Foley, M. A., Suengas, A. G., \& Raye, C. L. (1988). Phenomenal characteristics of memories for perceived and imagined autobiographical events. Journal of Experimental Psychology: General, 117, 371-376.

KLeIn, S. B., Cosmides, L., Tooby, J., \& Chance, S. (2002). Decisions and the evolution of memory: Multiple systems, multiple functions. Psychological Review, 109, 306-329.

KLEIN, S. B., LOFTUS, J., \& KIHLSTROM, J. F. (2002). Memory and temporal experience: The effects of episodic memory loss on an amnesic patient's ability to remember the past and imagine the future. Social Cognition, 20, 353-379.

LEVINE, B. (2004). Autobiographical memory and the self in time: Brain lesion effects, functional neuroanatomy, and lifespan development. Brain \& Cognition, 55, 54-68.

Levine, B., Freedman, M., Dawson, D., Black, S. E., \& Stuss, D. T. (1999). Ventral frontal contribution to self-regulation: Convergence of episodic memory and inhibition. Neurocase, 5, 263-275.

LogAN, G. D. (1988). Toward an instance theory of automatization. Psychological Review, 95, 492-527.

Nelson, K., \& Fivush, R. (2004). The emergence of autobiographical memory: A social cultural developmental theory. Psychological Review, 111, 486-511.

OKuda, J., FujiI, T., Ohtake, H., Tsukiura, T., Tanji, K., Suzuki, K., ET AL. (2003). Thinking of the future and past: The roles of the frontal pole and the medial temporal lobes. NeuroImage, 19, 1369-1380.

Okuda, J., FujiI, T., Yamadori, A., KaWAShima, R., TsukiURa, T., FuKATSU, R., ET AL. (1998). Participation of the prefrontal cortices in prospective memory: Evidence from a PET study in humans. Neuroscience Letters, 253, 127-130.

Petry, N. M., BicKel, W. K., \& Arnett, M. (1998). Shortened time horizons and insensitivity to future consequences in heroin addicts. Addiction, 93, 729-738.

PILlEMER, D. B. (2003). Directive functions of autobiographical memory: The guiding power of the specific episode. Memory, 11, 193-202.

Roberts, W. A. (2002). Are animals stuck in time? Psychological Bulletin, 128, 473-489.

RUBIN, D. C. (1980). 51 properties of 125 words: A unit analysis of verbal behavior. Journal of Verbal Learning \& Verbal Behavior, 19, 736-755.

RUBIN, D. C. (1982). On the retention function for autobiographical memory. Journal of Verbal Learning \& Verbal Behavior, 21, 21-38.
Rubin, D. C., \& Schulkind, M. D. (1997). The distribution of autobiographical memories across the lifespan. Memory \& Cognition, 25, 859-866.

RUBiN, D. C., \& Wenzel, A. E. (1996). One hundred years of forgetting: A quantitative description of retention. Psychological Review, 103, 734-760.

SchroOTS, J. J. F., van DiJkum, C., \& Assink, M. H. J. (2004). Autobiographical memory from a life span perspective. International Journal of Aging \& Human Development, 58, 69-85.

SEMIN, G. R., \& SMITH, E. R. (1999). Revisiting the past and back to the future: Memory systems and the linguistic representation of social events. Journal of Personality \& Social Psychology, 76, 877-892.

SQuire, L. R., \& Zola-Morgan, S. (1991). The medial temporal lobe memory system. Science, 253, 1380-1386.

Stevens, S. S. (1961). To honor Fechner and repeal his law. Science, 133, 80-86.

STEVENS, S. S. (1970). Neural events and the psychophysical law. Science, 170, 1043-1050.

SuDDENDORF, T., \& BusBy, J. (2003). Mental time travel in animals? Trends in Cognitive Sciences, 7, 391-396.

SUDDENDORF, T., \& BUSBY, J. (2005). Making decisions with the future in mind: Developmental and comparative identification of mental time travel. Learning \& Motivation, 36, 110-125.

Suddendorf, T., \& Corballis, M. C. (1997). Mental time travel and the evolution of the human mind. Genetic, Social, \& General Psychology Monographs, 123, 133-167.

Svoboda, E., McKinnon, M. C., \& Levine, B. (2006). The functional neuroanatomy of autobiographical memory: A meta-analysis. Neuropsychologia, 44, 2189-2208.

TroPE, Y., \& LiBERMAN, N. (2003). Temporal construal. Psychological Review, 110, 403-421.

Tulving, E. (1985). Memory and consciousness. Canadian Psychology, 26, 1-12.

Tulving, E. (2002). Episodic memory: From mind to brain. Annual Review of Psychology, 53, 1-25.

WALLACE, M. (1956). Future time perspective in schizophrenia. Journal of Abnormal \& Social Psychology, 52, 240-245.

Wheeler, M. A., Stuss, D. T., \& Tulving, E. (1997). Toward a theory of episodic memory: The frontal lobes and autonoetic consciousness. Psychological Bulletin, 121, 331-354.

Williams, J. M. G., Ellis, N. C., Tyers, C., Healy, H., Rose, G., \& MACLEOD, A. K. (1996). The specificity of autobiographical memory and imageability of the future. Memory \& Cognition, 24, 116-125.

Wilson, B. A., \& Wearing, D. (1995). Prisoner of consciousness: A case of just awakening following herpes simplex encephalitis. In R. Campbell \& M. A. Conway (Eds.), Broken memories: Case studies in memory impairment (pp. 14-30). Oxford: Blackwell.

Worthington, A. (1999). Dysexecutive paramnesia: Strategic retrieval deficits in retrospective and prospective remembering. Neurocase, 5, 47-57.

Zimbardo, P. G., \& Boyd, J. N. (1999). Putting time in perspective: A valid, reliable individual-differences metric. Journal of Personality \& Social Psychology, 77, 1271-1288.

(Manuscript received June 8, 2005; revision accepted for publication September 22, 2005.) 